\title{
Aa. Vv., «Fréquences francophones. Revue de l'Association des professeurs de et en français de Bulgarie», n. 7
}

\section{Maria Chiara Gnocchi}

\section{(2) OpenEdition}

\section{Journals}

Édition électronique

URL : https://journals.openedition.org/studifrancesi/46354

DOI : $10.4000 /$ studifrancesi.46354

ISSN : 2421-5856

Éditeur

Rosenberg \& Sellier

\section{Édition imprimée}

Date de publication : 1 octobre 2007

Pagination : 483-484

ISSN : 0039-2944

\section{Référence électronique}

Maria Chiara Gnocchi, «Aa. VV., «Fréquences francophones. Revue de l'Association des professeurs de et en français de Bulgarie», n. 7 », Studi Francesi [En ligne], 152 (LI | II) | 2007, mis en ligne le 30 novembre 2015, consulté le 24 novembre 2021. URL : http://journals.openedition.org/studifrancesi/ 46354 ; DOI : https://doi.org/10.4000/studifrancesi.46354

Ce document a été généré automatiquement le 24 novembre 2021.

\section{cc) $(1) \odot$}

Studi Francesi è distribuita con Licenza Creative Commons Attribuzione - Non commerciale - Non opere derivate 4.0 Internazionale. 


\title{
Aa. Vv., «Fréquences francophones. Revue de l'Association des professeurs de et en français de Bulgarie», n. 7
}

\author{
Maria Chiara Gnocchi
}

\section{RÉFÉRENCE}

«Fréquences francophones. Revue de l'Association des professeurs de et en français de Bulgarie», n. 7, 2006, pp. 74.

1 Il est fortement souhaitable que, grâce à l'intégration récente de la Bulgarie dans l'Union européenne, la coopération intellectuelle s'amplifie entre ce pays et le reste du monde. On connaît la francophilie de la Bulgarie, ainsi que les grands maîtres qu'elle a enfantés. On connaît peut-être moins la jeune génération de chercheurs, une génération décidément prometteuse, qui a déjà donné plusieurs signes tangibles de sa productivité. C'est dans ce cadre qu'il convient de prendre connaissance de Fréquences francophones, publication semestrielle de l'Association des professeurs de et en français de Bulgarie ( $\mathrm{ApfB},<\mathrm{www}$.ceco-fipf.org $>$ ), gérée et animée par de très jeunes gens, qui en est déjà à son septième numéro. Dans cette livraison figurent deux dossiers: un dossier proprement dit, ayant comme sujet la traduction, et un deuxième groupe d'articles assez brefs, contenus dans la rubrique «Espaces francophones», sur «La représentation du temps dans les littératures francophones». Dans le premier de ces textes, Toader SAULEA (Université de Bucarest) rend hommage à Léopold Sédar Senghor, qui a su «édifier [...] le pont interculturel de l'Afrique et de l'Europe, en abolissant poétiquement l'espace géographique et le temps mental, en traduisant la mélancolie personnelle et temporelle en poème de la mélancolie humaine, universelle et atemporale» (p. 30). Suit un aperçu, par Geneviève CHOVReLAT (Université de Franche- 
Comté), sur la littérature acadienne et sur le travail de mémoire qu'elle opère, l'Acadie étant un pays qui, selon la définition d'Antonine Maillet, «n'a pas de lieu, mais qui a du temps». Dans la troisième contribution, Sophie LÉTOUMEAU (Université de Montréal) analyse Le Grand Incendie de Londres de Jacques Roubaud (1989) en se démarquant de la perspective traditionnelle des études autobiographiques: son but est plutôt de réfléchir sur «l'écriture du réel passé» (p. 34). Rennie yotova (Université de Sofia «St. Kliment Ohridski»), rédactrice en chef de Fréquences francophones, consacre un article à l'écrivaine suisse contemporaine Asa Lanova, et en particulier aux romans Le Blues d'Alexandrie (1998) et Les Jardins de Shalalatt (2001), étudiés par le biais du mythe d'Hypatie, astronome et mathématicienne légendaire du ve siècle. Dans les deux livres, Alexandrie se manifeste comme une ville textuelle, ce qui permet à l'auteur d'établir un rapport intertextuel, basé sur la conception de la littérature comme mémoire, entre la ville et son propre texte: «Le texte de la ville d'Alexandrie est un vaste hypotexte disparu sur lequel les personnages des romans de Lanova vont essayer de construire un hypertexte moderne» (pp. 39-40). R. Matilde MÉSAVAGE (Department of Modern Languages and Literatures, Rollins College, Florida - on remarquera les provenances tous azimuts des contributeurs) consacre une dernière étude à la temporalité dans $\mathrm{Tu}$ arrêtes le temps, une nouvelle d'olga Boutenko, écrivaine canadienne d'origine russe, parue dans le recueil bilingue Aélita (1994). Dans cette nouvelle, les montres et le réveille-matin de la protagoniste se bloquent inexplicablement: c'est l'occasion, pour l'auteur, d'explorer «les rapports entre le temps et la liberté, le temps et l'espace, le temps et les émotions aussi bien que le temps et l'éternité» (p. 42). La rubrique se clôt par une interview -intitulée "La bibliothèque, un espace de liberté» - avec Lise Bissonnette, écrivaine et journaliste québécoise, réalisée par Rennie уотоvA. Fréquences francophones présente également une rubrique d'informations diverses (dans les domaines de la linguistique et de la littérature) et une série de comptes rendus. 